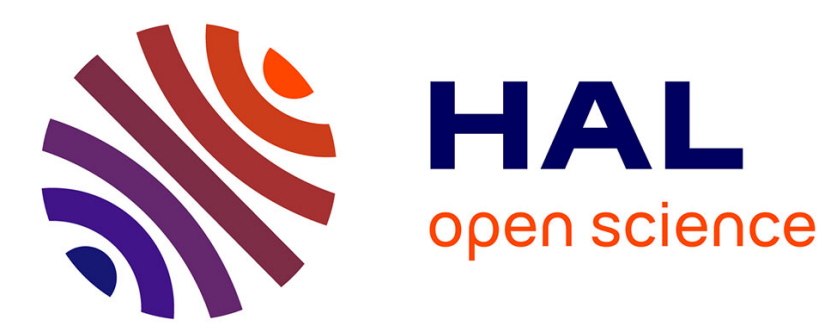

\title{
ELECTRICAL PROPERTIES OF COBALT DOPED SILICON BICRYSTALS
}

\author{
P. Damecourt, G. Nouet
}

\section{To cite this version:}

P. Damecourt, G. Nouet. ELECTRICAL PROPERTIES OF COBALT DOPED SILICON BICRYSTALS. Journal de Physique Colloques, 1990, 51 (C1), pp.C1-457-C1-462. 10.1051/jphyscol:1990171 . jpa-00230339

\section{HAL Id: jpa-00230339 https://hal.science/jpa-00230339}

Submitted on 1 Jan 1990

HAL is a multi-disciplinary open access archive for the deposit and dissemination of scientific research documents, whether they are published or not. The documents may come from teaching and research institutions in France or abroad, or from public or private research centers.
L'archive ouverte pluridisciplinaire HAL, est destinée au dépôt et à la diffusion de documents scientifiques de niveau recherche, publiés ou non, émanant des établissements d'enseignement et de recherche français ou étrangers, des laboratoires publics ou privés. 
COLLOQUE DE PHYSIQUE

Colloque C1, supplément au $\mathrm{n}^{\circ} 1$, Tome 51, janvier 1990

ELECTRICAL PROPERTIES OF COBALT DOPED SILICON BICRYSTALS

P. DAMECOURT and $G$. NOUET

Laboratoire d'Etudes et de Recherches sur les Matériaux, CNRS URA 1317, Institut des sciences de la Matière et du Rayonnement, Boulevard du Maréchal Juin, F-14032 Caen Cedex, France

Résumé - Les propriétés électroniques de bicristaux de silicium dopés au cobalt ont été étudiées par spectroscopie des transitoires des niveaux profonds en utilisant la capacité du joint de grains. Les bicristaux ont l'orientation $\Sigma 25$. Après dépôt d'une couche de cobalt les échantillons sont recuits et refroidis soit lentement soit par trempe. Les conditions de refroidissement sont les parametres les plus importants et modifient fortement les spectres DLTS obtenus qui montrent des pics discrets ou des continuums étroits.

Abstract - Electronic properties of cobalt doped silicon bicrystals have been investigated by a modified deep level transient spectroscopy using the capacitance of the charged grain boundary. The geometric characteristics are $\sum 25,16^{\circ} 26<001>$, grain boundary plane $\{710\}$ and a doping of $3.610^{14}$ phosphorus atom. $\mathrm{cm}^{-3}$. Cobalt diffusion times $(15,30$ and $60 \mathrm{mn})$ are followed by two types of cooling : i) quenching with cooling rate of about $20^{\circ} \mathrm{C} / \mathrm{s}$; ii) slow cooling down to $750^{\circ} \mathrm{C}$ and quenching with approximately the same cooling rate. These different thermal treatments result in a wide variety of spectra characterized by several peaks. Comparison with samples without cobalt is given.

\section{1 - INTRODUCTION}

Polycrystalline silicon devices have many important applications in the field of photovoltaic conversion or microelectronic. However the crystallographic defects such as high angle or low angle grain boundaries can play a major role on their electronic characteristics. For instance, an important drop of the photovoltaic yield has been observed with polycrystalline silicon instead of monocrystalline. Several previous studies have shown the morphology of polycrystalline silicon involves a large amount of coincidence or near coincidence grain boundaries which can be electrically active or not. Firstly, the geometric structure of these grain boundaries has been widely studied in order to correlate the dangling bonds which were supposed to exist within a grain boundary with the electrical activity of these grain boundaries observed by EBIC. Recently it has been established in germanium by HREM /1-2/ that the structural units which make up the coincidence or near coincidence grain boundaries are fully reconstructed and that these special grain boundaries are electrically active after some thermal treatments $/ 3 /$. The origin and conditions of this electrical activity are now wellknown and attibuted to the formation of precipitates $/ 4-7 /$. Then these precipitates have been identified as $\eta^{\prime \prime}-5 i_{3} \mathrm{Cu}$ silicide /8/. 
The identification of these metallic silicides as origin of the electrical activity observed at grain boundaries emphasizes the assumption that segregation or precipitation are more efficient than dangling bonds. In this present work the influence of an another fast diffuser, cobalt, on the electronic properties of grain boundaries has been investigated. Recent studies of the cobalt contamination of silicon grain boundary have shown that the observed enrichement of cobalt in the grain boundary is due to $\cos _{2}$ precipitates $19 /$.

\section{2 - MEASUREMENT OF INTERFACE STATES}

Deep-level transient spectroscopy (DLTS) is now a well established method to determine traps in semiconductors $/ 12 /$. This technique is based on the filling or emptying of traps at different temperatures. By using a dual-gate correlator it is possible to form the DLTS signal from a capacitance transient and by measuring the variation of this signal as a function of the temperature a DLTS spectrum can be obtained. Recently this method has been applied to grain boundary of bicrystals. In the case of bicrystals, an electrostatic potential barrier can be associated with the grain boundary. This potential barrier results from the filling of interface states due to cristallographic or chemical defects lying in the boundary plane. In this experiment, periodic voltage pulses are applied across the boundary to vary the occupancy of the interface traps. Between successive pulses, the boundary charge relaxes towards equilibrium by thermal emission of the excess trapped carriers. The relaxation of the boundary charge is detected by the corresponding variation of the boundary capacitance. All details of this analysis can be found in Broniatowski's paper /13/. From an experimental point of view this method enables the grain boundary electronic parameters such as energy level, state density and capture cross sections to be determined.

\section{3 - EXPERIMENTAL METHODS}

The silicon bicrystals were intentionally grown by czochralski method at LETI-Grenoble /10/. They are characterized by a rotation of $16.26^{\circ}$ around the common <001> axis which correspond to $\Sigma 25$ in terms of coincidence site lattice. The grain boundary plane is $\{710\}$. By measuring the shift of kikuchi maps between the adjacent grains a $0.15^{\circ}$ tilt deviation around [7i7] axis has been measured. This additional rotation is accommodated by a single network of edge dislocations with the Burgers vector $1 / 50$ [710] /11/.

The silicon bicrystals were $n$-type (P-doped) with $\mathrm{N}_{0} \simeq 3 \times 10^{14} \mathrm{~cm}^{-3}$. The initial oxygen and carbon concentrations were $5 \times 10^{17}$ and $0.75 \times 10^{17} \mathrm{at} . \mathrm{cm}^{-3}$ respectively. Heat treatments were performed in argon using an open tube quartz furnace. To determine the influence of cobalt, it was firstly electrodeposited in a aqueous $\left(\mathrm{NO}_{3}\right)_{2} \mathrm{Co}$ solution on the four faces of a parallelipiped (10 $33 \times 3 \mathrm{~mm}^{3}$ ) with the boundary plane perpendicular to the greatest dimension. To perform DLTS experiments ohmic contact were made on the two faces parallel to the grain boundary. Heat treatments were performed with two bicrystals: one in as grown state and the other after cobalt deposition. Thermal cycles were chosen in order to check the 
influence of the annealing length and of the cooling speed. So the samples were introduced at room temperature, and the annealing temperature $\left(950^{\circ} \mathrm{C}\right)$ was reached after $1 \mathrm{~h} 30$. The annealing time is varying in the range 15, 30 and $60 \mathrm{mn}$. Two types of cooling were considered either by quenching or by slow cooling.

\section{4 - RESULTS AND DISCUSSION}

In the as-grown state the silicon bicristal exhibits no potential barrier and so no DLTS measurement can be carried out. In fact, in this state, the bicristal is quite similar to a monocristal and the measured conductance corresponds to that of the monocristal. This result confirms the conductance measurements obtained on the same type of bicrystals by the four-probe method in the temperature range 100-300 $\mathrm{K} / 14 /$. The transport of the majority carriers is unchanged by the grain boundary and the secondary dislocation network has no electrical effect.

The influence of the cooling speed has been investigated for the three following treatments : quenching, slow cooling from 950 to $750^{\circ} \mathrm{C}$ and quenching, slow cooling. The corresponding DLTs spectra are given in Fig. 1. This figure shows two types of spectra. Both spectra obtained after total or partial quenching display a single peak which can be considered as a narrow continuum whereas after slow cooling two discrete peaks are obtained. For the thermal cycles including partial or total quenching, this stage determines the shape of the DLTS spectra and consequently the distribution of the grain boundary states. These new results confirm our previous results $/ 4 /$.

The origin of the formation of these potential barriers at grain boundaries has been attributed to copper silicide decorating the grain boundary plane with colonies of small precipitates $/ 7,8 /$. These silicide precipitates have a metallic character and can give rise to a non-ohmic contact between the precipitates and the silicon bulk. Recently such an interpretation of these electrical properties based on the schottky-Mott theory of metal-semiconductor contacts has been given by Broniatowski /15/.

To emphasize theses electrical properties of grain boundaries due to metallic impurities cobalt was electrodeposited on the faces of the samples and then annealed in the same conditions. For these cobalt doped silicon bicrystals the DLTS spectra show some specific features but also common points with the bicrystals without cobalt. The common points are the effects of the thermal cycles for which quenching remains the most important stage.

In this case a discrete peak is now obtained with the energy $E_{c}-0.54 \mathrm{eV}$ after quenching (Fig. $2 \mathrm{a}$ ) and $\mathrm{E}_{c}-0.28 \mathrm{eV}$ after quenching from $750^{\circ} \mathrm{C}$ (Fig. 2b). These peaks are characteristic of a single level now instead of a narrow continuum. After slow cooling a discrete peak is obtained at $E_{c}-0.64 \mathrm{eV}$. Precipitation of CoSi $i_{2}$ silicide is expected and could explain the different spectra obtained. However further investigations based on electron microscopy and microanalysis are needed to know the exact nature of the precipitate, their shape and distribution in the grain boundary plane. The contribution of there different parameters could be analyzed and connected to the shape of the spectra. 

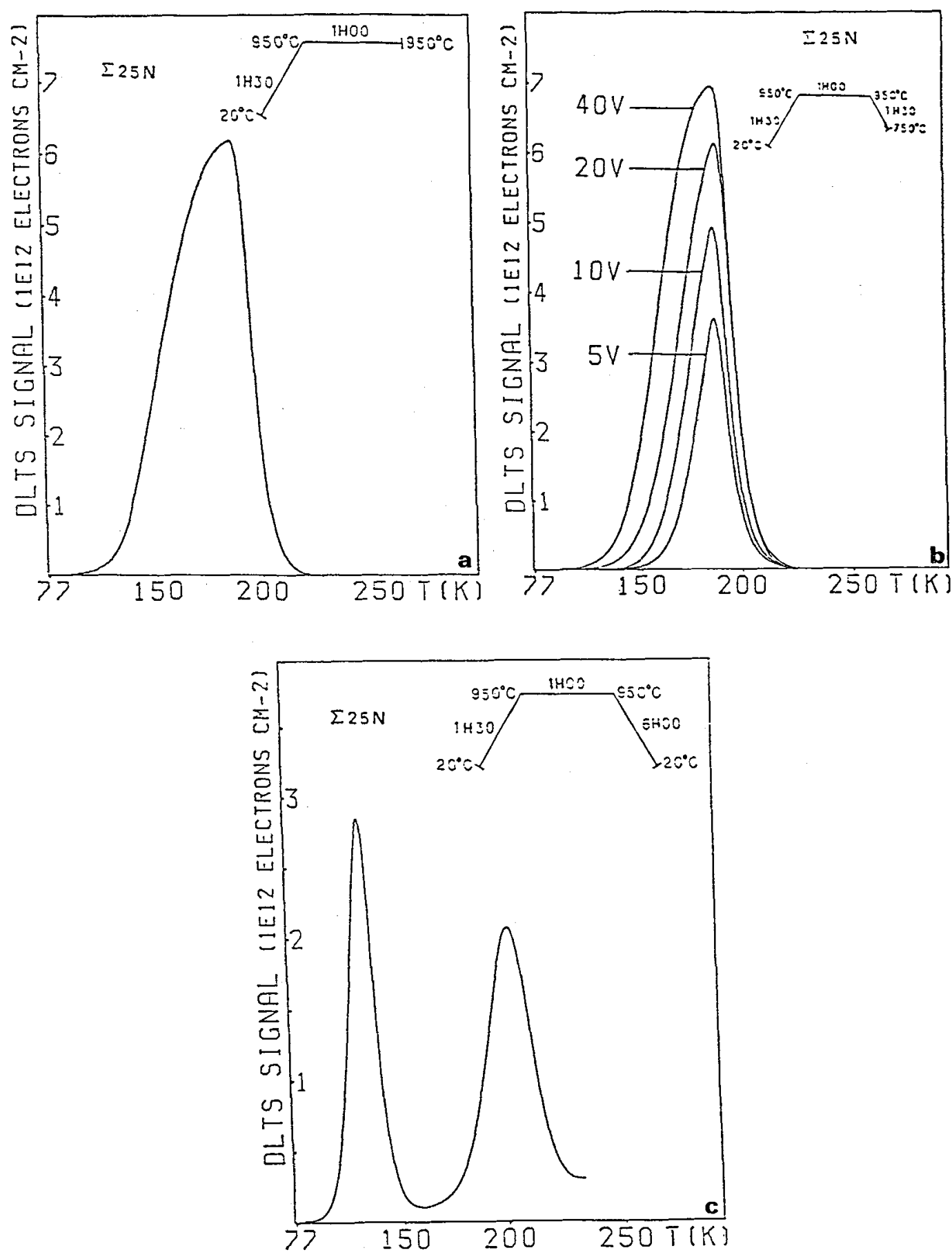

Fig. 1 : DLTS spectra of the $\sum 25$ as grown silicon bicrystal after different thermal treatments, pulse duration loms. a) quenching from $950^{\circ} \mathrm{C}$, impulsion pulse $50 \mathrm{~V}$, emission rate $19 \mathrm{~s}^{-1}$ and b) quenching from $750^{\circ} \mathrm{C}$, emission rate $14 \mathrm{~s}^{-1}$, show narrow continuum and c) slow cooling, impulsion pulse $6,5 \mathrm{~V}$, emission rate $19 \mathrm{~s}^{-1}$, show two discrete peaks. 

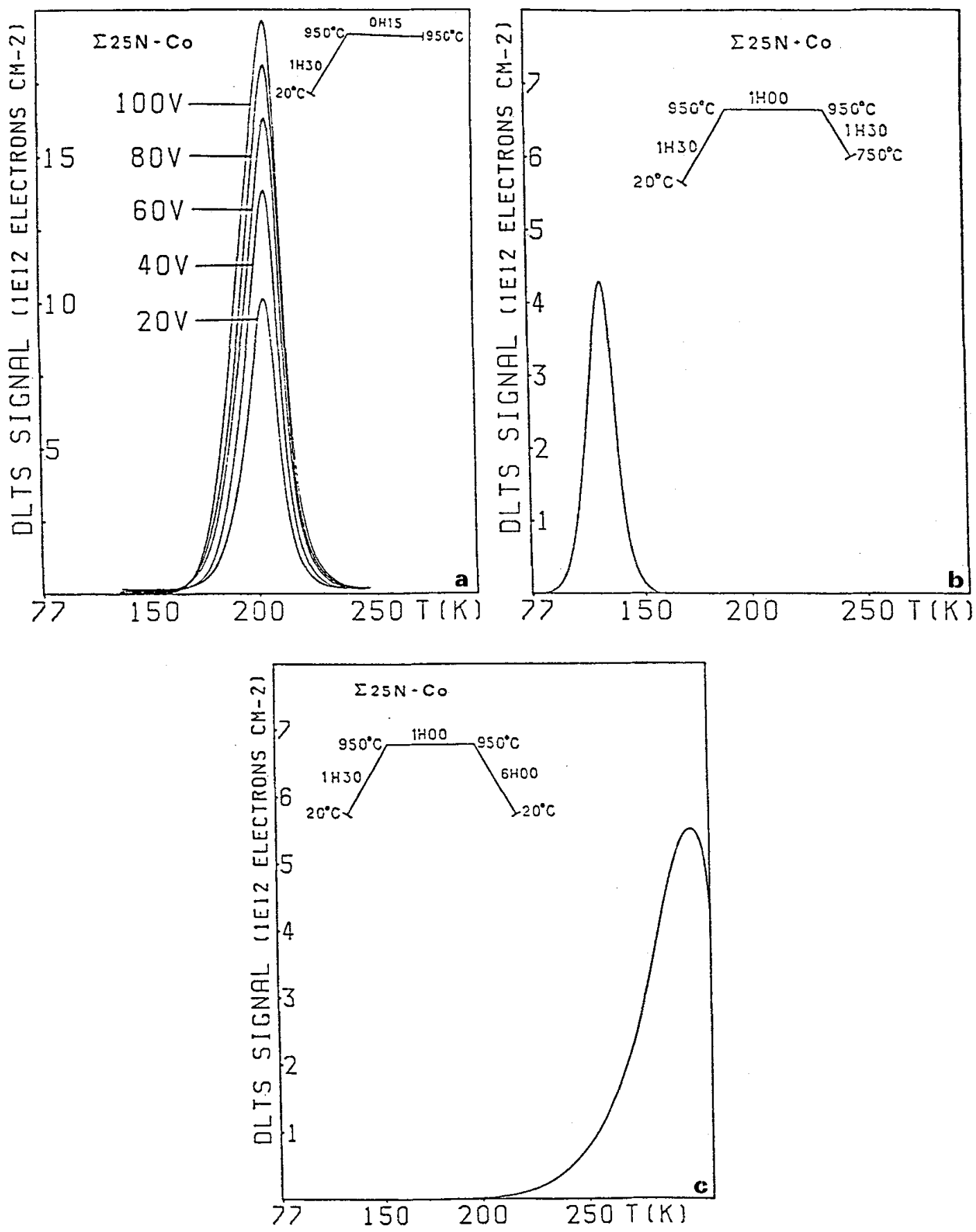

Fig. 2 : DITS spectra of the $\Sigma 25$ cobalt doped silicon bicrystal after different thermal treatments, pulse duration $10 \mathrm{~ms}$. a) quenching from $950^{\circ} \mathrm{C}$, emission rate $11 \mathrm{~s}^{-1}$ and b) quenching from $750^{\circ} \mathrm{C}$, emission rate $19 \mathrm{~s}^{-1}$, impulsion pulse $10 \mathrm{~V}$, and c) slow cooling, emission rate $11 \mathrm{~s}^{-1}$, impulsion pulse $18 \mathrm{~V}$. 


\section{5 - CONCLUSION}

The introduction of metallic impurities in silicon bicrystals modifies strongly the electrical properties of the grain boundaries. The formation of the potential barrier at the grain boundaries in the undoped material is attributed to metallic precipitates such as copper silicide. Cobalt diffusion gives rise at similar spectra to those obtained with copper for the thermal treatments with quenching.

\section{REFERENCES}

(1) Bourret, A. and Rouvière, J.L., Polycrystalline Semiconductors Ed: Möller, H.J., Strunk, H.P. and Werner, J.H., Springer Proceedings in physics, Vol. 35 p. 8 (1989).

(2) Rouvière, J.L. and Bourret, A., Polycrystalline semiconductors Ed: Möller, H.J., Strunk, H.P. and Werner, J.H., Springer Proceedings in Physics, Vol. 35 p. 19 (1989).

(3) Battistella, F., Rocher, A. and George, A., Oxygen, Carbon, Hydrogen and Nitrogen in Crystalline Silicon. Ed : Mikkelsen, J.C., Jr, Pearton, S.J., corbett, J.W. and Pennycook, S.J., Materials Research Society, Symposia Proceedings, Vol. 59 p. $347(1986)$.

(4) Hamet, J.F. and Nouet, G., Polycrystalline semiconductors Ed: Möller, H.J., Strunk, H.P. and Werner, J.H., Springer Proceedings in Physics, Vol. 35 p. 58 (1989).

(5) Aucouturier, M., Broniatowski, A., Chari, A. and Maurice, J.L., Polycrystalline Semiconductors, Ed : Möller, H.J., Strunk, H.P. and Werner, J.H., Springer Proceedings in Physics, Vol. 35 p. 64 (1989).

(6) Ihlal, A. and Nouet, G., Polycrystalline semiconductors, Ed : Möller, H.J., Strunk, H.P. and Werner, J.H., Springer Proceedings in Physics, Vol. 35 p. 77 (1989).

(7) Maurice, J.L. and Colliex, C., Polycrystalline semiconductors Ed: Möller, H.J., Strunk, H.P. and Werner, J.H., Springer Proceedings in Physics, Vol. 35 p.83 (1989).

(8) Hamet, J.F., Abdelaoui, R., Nouet, G. and Allais, G., E-MRS Proceedings Science and Technology of Defects in Silicon, Strasbourg $30 \mathrm{Mai}-2$ Juin 1989.

(9) Tutken, T., schröter, W. and Möller, H.J., Polycrystalline Semiconductors, Ed : Möller, H.J., Strunk, H.P. and Werner, J.H., Springer Proceedings in Physics, Vol. 35 p. 108 (1989).

(10) Aubert, J.J. and Bacmann, J.J., Rev. Phys. Appl. 22 (1987) 515 .

(11) Bary, A., Nouet, G. and Delavignette, P., J. of Microsc. (to be published).

(12) Lang, D.V., J. Appl. Phys. 45 (1974) 3023.

(13) Broniatowski, A., Phys. Rev. B 36 (1987) 5895.

(14) Poullain, G., Mercey, B. and Nouet, G., J.Appl. Phys. 61 (1987) 1547 .

(15) Broniatowski, A., Phys. Rev. Let. $\underline{62}$ (1989) 3074 . 